THURSDAY, MARCH I5, 1877

\section{THE TREASURY REPORT ON METEOROLOGY}

X $\mathrm{E}$ gave in our last number the report of the Treasury Committee on the administration of the Government meteorological grant, and we shall now offer a few remarks on it and on the evidence upon which it has been founded, as contained in the Blue-book before us. ${ }^{1}$ The expenditure is devoted to the meteorology of the ocean, that is, to the part of it traversed by our ships and to that of the British Isles.

As regards the former, though much valuable work, especially in the practical point of view, has been done, this work belongs distinctly to a government department of the Admiralty. It does not seem desirable that charts for the direction of seamen should be made out according to different methods by two institutions, supported by national money. It is then proposed by the committee that the charting work, together with the marine superintendent of the Meteorological Office, who has done his duty so well, should be transferred to the Hydrographic Department of the Admiralty, while the scientific part should be done in connection with investigations, including observations both over land and sea. This appears a most reasonable decision.

Though the second part of the business of the Meteorological Office is limited to a small surface, yet it is one with which we are more immediately concerned, and surrounded as we are by the sea, this part really involves all the modifications which surfaces of land and water may produce on the actions of meteorological causes. It seems to be supposed that observations on the ocean must present meteorological variations in a much simpler form, because the atmosphere rests on a surface which is at once more level, and at a more constant temperature than that of the land; but it seems not to have been remarked that the conditions under which the observations are made are much more complex. If we could imagine a search into the laws of continental meteorology founded on the observations made by some passengers in railway trains across France, Germany, and Russia, the difficulty of piecing together observations of very various degrees of merit for the deduction of even accurate means would be at once evident ; that of searching forlaws would become still more so. It is no doubt desirable that the meteorological variations over water should be studied apart, but for this end an observatory placed on some small island in midocean would be a more satisfactory way of obtaining the end in view. Whether this would aid in the search for the causes of phenomena met with under very different conditions in our latitudes is by no means certain.

The department of the Meteorological Office occupied with the meteorology of the British Isles, includes that of storm warnings; indeed this is, at present, the great practical work. There are numerous stations at which "eye" observations are made daily, and these are telegraphed to the central office in London. There are also seven observatories having instruments which register

I " Report of the Treasury Committee Appointed to Inquire into the Conditions and Mode of Administration of the Annual Grant in aid of Meteoro logical Observations; together with Minutes of Evidence, Appendix, and Index." (London, I8 77 .)

Vol. $x v_{e}-N$ No. 385 continuously the variations "of the meteorological elements. The storm warnings are founded on the telegraphed observations; the registered observations have a different object. They can no doubt be employed after warnings have been issued to verify the observations and to satisfy any doubt that may have existed as to errors committed, but their chief object, in the first instance, is purely scientific.

It has long been seen that storm warnings are not founded upon laws that can be distinctly stated. Though observations made over a considerable tract of country are made use of, and a certain knowledge exists of relations between atmospheric pressure and winds, yet the warnings depend to some extent upon a practical experience which, like that of the shepherd and sailor, cannot easily be communicated to others.

The seven observatories were established to obtain good materials with which a scientific study might be founded and from which laws might be deduced giving increased probabilities of accurate prediction of the weather tomorrow from our knowledge of what it is to-day. This is not, however, the only use of the observatories. If all the scientific precautions have been taken with respect to them, they will in that case be to the meteorology of the country what carefully measured base lines are to its exact survey; each will give a point to which the observations made around it may be referred and corrected.

The great question before the Committee was how best to aid in making meteorology a science--a science from which practical results may be deduced. Millions of meteorological observations have been made and published; the seven observatories are producing continuous registers of the variations of barometric pressure, temperature, wind direction and force, \&c. What is to be done with all these? Are we to go on piling Pelion on Ossa with the idea that heaps of observations will enable us to reach the mysteries they enclose? And can the Government be satisfied that they have done enough when they present the public with volumes of observation in something of the way in which Hamlet offered his friend the pipe- "Govern these ventages with your fingers and thumb, give it breath with your mouth, and it will discourse most eloquent music"?

The question then is how to get at the mysteries; or how to find a musician with breath enough to blow and skill enough to draw harmonious sounds from this giant pipe. We can only glance at parts of the testimony of the most distinguished witnesses.

When we remember that after a century of research by men of the greatest eminence-mathematicians, physicists, meteorologists-we cannot tell why the air presses heavier at ten o'clock than at four o'clock; we see that meteorological investigation includes some of the most difficult scientific problems. With this fact in view, some of the questions put to the witnesses would seem almost comiques, did we not know that their object was to draw out something of value in the reply. Thus, with reference to finding a "man of genius to try and get something out of the observations which have been made" (I,OI2), the question ( 1,017 ) is put to Sir G. B. Airy : "But you would hardly think it a safe thing to select, for instance, a young man from Cambridge, and say to him: 'Now you must take up this subject'?" When we remember, also, that 
the Astronomer-Royal has directed a meteorological observatory nearly forty years, and that he now says meteorology is not a science (940), it is naught, and in short that he has not been able to make anything out of it, we can understand with what profound conviction he replied, "I do not think that would be a safe thing."

Sir William Thomson was also examined on this question, and he thinks (I720) "the best way would be to get some thoroughly able young man, well acquainted with mathematics and of good judgment to take up the whole subject of the harmonic analysis of the observations." No doubt the harmonic analysis has some advantages as representing mean values approximately by a series of simple oscillations occupying the whole, a half, a third, \&c., of the time-period considered, which can be compared when the conditions vary ; but it is only a first step, one which may be misused if it is supposed that each oscillation must represent the different periodic actions of the same or of different causes. Kaemtz employed this method forty years ago on every possible meteorological variation, but we cannot say that any important result was obtained by its means.

What has to be done was indicated by the AstronomerRoyal in answer to question 1,O15) ; men (one man cannot undertake the work in all its directions) must be "seized upon" who have displayed "talent for things of that sort," who by long study have become saturated with the facts of the science and who have shown the capacity to devise new methods and to employ them with success. Such men, as Sir George Airy says, in answer to another question (99I), should be asked to devote themselves to examining the observations already made, and to "turning them over in all conceivable ways." Such men, he says (I,OI5), are to be taken "on opportunity," that is to say, if they present themselves we should lay hold of them. But this is true for every occupation demanding special qualifications. It would seem sometimes as if the difficulties were exaggerated, and sometimes under estimated. If we had a Newton among us, he could do little till the meteorological apple has fallen, and the tree will require, we think, a good deal of shaking first. That the specialty of turning a thing " in all conceivable ways" is not very common, may be deduced from the evidence before the committee; but many look on meteorological investigation as a kind of lottery, where just because so many blanks have been drawn, every one has a better chance of getting a prize; and some very clever people think that the affair may be done by a machine.

There is also the very urgent reason for "turning over" the observations made at the seven observatories, that it is not possible to determine their value, nor how far they can be usefully employed for strict scientific investigation till this is done. Mr. Buchan, one of the few working meteorologists examined, says $(1,530)$, that the eye-observations "secure an exactness and accuracy which photographic self-recording instruments do not possess." This, if true, is a very serious matter, and we shall have to return to it at another time.

The subject of observatories, the most important in connection with the progress of meteorology as a science, was also brought forward by the Committee. The question was put to the Astronomer-Royal $(\mathrm{I}, 045)$ : "Might I ask what led your office to undertake the meteorological part of its work in I840?-Because nobody else did." This answer must evidently be taken with reference to certain conditioris. Had the Government been encouraged at the time to support a magnetical and meteorological observatory, paying a competent man to direct it, we can scarcely doubt that they would have done so. Sir G. Airy's reply means, we believe, that nobody was ready to undertake the duty for nothing; but himself. We think it is much to be regretted that the director of the National Observatory, overcharged as he is with the duties connected directly with his office, should have been allowed to undertake scientific work, demanding so much care and devotion of time, which was really not at all in his specialty, however excellent the motives might have been which induced him to do so.

This is now well understood in other countries. In Paris there is now a magnetical and meteorological observatory with a distinct head; another observatory devoted to solar physics is rising; and similar arrangements have been made in Germany and Austria. It is the very essence of "penny wise, pound foolish" which can seek from one man to direct with success three or four observatories at the same time, when each of them will task the energies of the cleverest men in the different departments to make something good out of them.

The question is further put $(\mathrm{I}, 050)$ - "In the former part of your evidence you spoke as if meteorology at present was scarcely in a scientific position at all, as too uncertain to be called a science at present?-It is not in a scientific condition at all, I think."

"I,05 I.-I want to connect that answer with the fact that in 1840 you undertook in this Government Department these particular inquiries; at that time you must have formed some idea that these studies were worth pursuing for national objects, and in a national establishment?-Observing the movement that was going on in other places, it was very desirable that Greenwich should be one of the stations in concert with them, but still I was so diffident about the success of it, that after three years, I think at the next meeting of the committee, or I forget by what name it was called, where the representatives of different nations attended, I earnestly urged them to cease. I did not see that there was any use in going on. I recommended them to do something like what I have spoken of to-day, to stop where they were, and try what they could extract from those observations that they had collected, before they proceeded further with them."

It has always been a tendency with the heads of great national scientific institutions to annex other scientific work than that for which the institutions were founded. We remember that the late Prof. Nichol described at the meeting of the British Association at Glasgow in 1840 , the numerous works he was about to carry forward in different departments of astronomy ; to all he added a magnetical and also a meteorological observatory, with special reference to important meteorological problems, which he proposed to take up. Photoheliography and spectroscopy were not then in existence, or doubtless they also would have been included. The Astronomer-Royal then said (we do not remember the exact words, but they were to this effect): "Let me, as 
an old observer, recommend Professor Nichol, as a young observer, to undertake less and he will do more."

We have much pleasure in finding that we agree so generally with Sir G. Airy's views. We do not think, however, that it was desirable to place a meteorological observatory in Greenwich Park. We have already said why we do not think it was necessary, or even advantageous to the sciences, that both magnetism and meteorology should be placed under the same direction as the National Astronomical Observatory. Indeed the Astronomer-Royal has allowed (in his evidence) for meteorology, what is well known to scientific men all over the world for magnetism, that his well-intentioned devotion to these subjects has not been repaid by the results he has obtained.

Sir G. Airy thinks the existence of the Kew Observatory unnecessary $(1,028)$; that they can furnish observations "at Greenwich as good or better, but quite as good certainly" (995). We quite agree that Kew and Greenwich are not both necessary, but it will be seen that we would greatly prefer to see magnetism and meteorology relegated elsewhere (we do not admire the position of Kew). With reference to the comparative value of the observations made at the two observatories, it has always been to us a matter of surprise that with two observatories within a few miles of each other, no comprehensive, strictly accurate, and scientific comparisons of the observations, magnetical and meteorological, made in them, should have been made and published. We cannot tell how far they agree or disagree. One might at least have been used as an aid to the other; if there are differences, such a comparison would have led to a search for their causes, and errors might thus have been corrected. It would be a very disagreeable matter if, when compared, instruments at the two observatories should be found not to go together as well as Admiral Fitzroy's weather-glass and an aneroid barometer.

A great national observatory for the prosecution of a branch of science of so much practical importance as meteorology should not be merely observational, but also experimental. Let us take one of the simplest cases, one brought forward before the Committee : How should we place a thermometer? Sir G. Airy says (984): "The mere observation of getting the temperature of the air is one of the most difficult things I know. If you are on the north side of a building within some distance you get it too low; if you are on the south side you get it too high, and if you are close to the ground you get something different." This is all perfectly exact ; and we may add, if you keep the thermometer in one place probably the sun will shine on the ground near it differently at different hours of the day and in different months of the year, so that there is a varying source of error in the same place. The Astronomer-Royal is also asked if he can estimate the probable difference between a thermometer at four feet and forty feet above the ground (987), but he cannot; and at what height a thermometer should be placed, but he replies only that four feet is the usual height.

We mention these questions to show that nearly everything has as yet to be placed on a scientific footing. We do not think four feet is a good height, and agree with the Astronomer-Royal that thermometers have been placed too near the ground, where they have been affected by many local differences which would have been to a great extent avoided at a greater height. Of course observations may be made at any height from the soil when special questions are in view. Similar difficulties exist for other instruments, and it is certain that we are making masses of observations which might have been much more valuable to science had experiments of the class indicated been made in the first instance. In such an observatory, also, there is a whole series of physical experiments which could and should be performed, indepen dently of those which should more properly be placed in the hands of specialists.

In the Report of the Committee, we find the following (Art. 8) :- "As regards the first, although it may be desir. able at some future time to create a permanent meteoro. logical establishment on some such fonting as that of the Astronomical Observatory at Greenwich, with an officer of scientific eminence at its head, we think that matters are scarcely ripe for such a step at present." We have been in some cases satisfied with the report, but here, if we understand the meaning of the word "ripe," we must differ. We believe that matters have been ripe any time the last forty years ; but we hope to return to this subject on another occasion.

The Report of the Committee is all that could probably be expected with the evidence before it. There are at present two purely scientific works that should be carried forward. Something should be done with the observations of the seven observatories, and much should be done to encourage research in connection with meteorological questions generally. It should not be imagined that an investigation with reference to some very small variation can have no practical value, that is to say, that the practical resuits which may flow from it can be measured by the amount of the variation. Nor should it be supposed that any question which touches on atmospheric variations should be neglected, in this respect; because the relation may appear remote. The movements of the sun's envelopes, the spots, the protuberances; the moon's possible action on solar emanations may all appear unconnected with our calms or our storms, and may yet all have a relation to both.

To conclude, we object to a cumulation of duties on one head, by which things are not only not well done, but through which others are prevented from doing them well. We think centralisation hurtful to science, and we regret that $1,000 l$. a-year has not been granted to Scotland, by which a healthy rivalry would have been gained.

We have given most place to Sir G. Airy's testimony because his is 'really the most important, but we cannot help inquiring why so few directors of observatories and meteorologists were examined. Dr. Lloyd, who has directed a magnetical and meteorological observatory for many years; Prof. Balfour Stewart, once secretary to the Meteorological Committee and director of the Kew Observatory ; Mr. J. A. Broun, who has directed observatories in Scotland and in India; the Rev. Mr. Main, director of the Radcliffe Observatory; Prof. Piazzi Smyth, director of the Edinburgh Observatory ; all of whom have been occupied with meteorological investigation, are all wanting, and they are all men who might have said something worth hearing on what should be done. 